\title{
Lumps and Bumps of the Abdominal Wall and Lumbar Region-Part 2: Beyond Hernias
}

\author{
Sangoh Lee ${ }^{1}$ Catalin V. Ivan ${ }^{1}$ Sarah R. Hudson ${ }^{1}$ Tahir Hussain ${ }^{1} \quad$ Suchi Gaba ${ }^{2} \quad$ Ratan Verma ${ }^{1}$ \\ Arumugam Rajesh ${ }^{1}$ James A. Stephenson ${ }^{1}$
}

${ }^{1}$ Department of Radiology, University Hospitals of Leicester, Leicester General Hospital, Leicester, United Kingdom

2Department of Radiology, University Hospitals of North Midlands, Royal Stoke University Hospital, Stoke-on-Trent, United Kingdom

\begin{abstract}
Address for correspondence James A. Stephenson, MD, FRCR, Department of Radiology, University Hospitals of Leicester, Leicester General Hospital, Leicester, LE5 4PW, United Kingdom (e-mail: james.stephenson@uhl-tr.nhs.uk).
\end{abstract}
Abstract
Keywords
- abdominal wall
- hernia
- mimics

Abdominal masses can often clinically mimic hernias, especially when they are located close to hernial orifices. Imaging findings can be challenging and nonspecific with numerous differential diagnoses. We present a variety of pathology involving the abdominal wall and lumbar region, which were referred as possible hernias. This demonstrates the wide-ranging pathology that can present as abdominal wall lesions or mimics of hernias that the radiologist should be alert to.

\section{Introduction}

An abdominal hernia occurs when an organ of a body cavity protrudes through a defect in the wall of that cavity. ${ }^{1}$ It is a common condition with lifetime risk of developing a groin hernia being estimated at $27 \%$ for men and $3 \%$ for women; it has thus been covered extensively in the literature. ${ }^{2}$ Imaging studies in the diagnosis of hernias were previously used only when the typical expected signs and symptoms of hernias were absent; however, many surgeons now prefer to have confirmatory imaging prior to invasive corrective surgery. Abdominal masses can often clinically mimic hernias, especially when they are located close to hernial orifices. Imaging findings can be challenging and nonspecific with numerous differential diagnoses.

We present a variety of hernia mimics throughout the abdominal wall and lumbar region. These were referred as possible hernias. This demonstrates the wide-ranging pathology that can present as abdominal wall lesions or mimics of hernias that the radiologist should be alert to.

\section{Benign Soft Tissue Lesions}

\section{Lipoma}

A lipoma is a benign mesenchymal tumor, which accounts for approximately one-half of all soft tissue tumors. ${ }^{3-5}$ Although it is in itself a benign entity that does not require surgical resection, it closely resembles more sinister tumors such as atypical lipomas and liposarcoma. Atypical lipomas and well-differentiated liposarcomas are histologically identical. The term "atypical lipoma" was coined by Evans et al in 1979 to describe well-differentiated liposarcoma of subcutaneous and intramuscular layers. ${ }^{6}$ The World Health Organization (WHO) has further refined the definition by using atypical lipoma to describe subcutaneous lesions only and well-differentiated liposarcoma for lesions elsewhere. ${ }^{7}$ The differentiation is of importance as well-differentiated liposarcomas are more likely to recur after resection and/or de-differentiate into high-grade sarcoma. ${ }^{6}$ Diagnosis of a simple lipoma can be made with relative certainty on ultrasound scan (USS) where the lesion is of homogenous fat echogenicity ( - Fig. 1) and on computed tomography (CT) demonstrates fat attenuation. On magnetic resonance imaging (MRI), the lesion is of pure fat signal on all sequences and may contain a few thin fibrous septa, which are low signal on both T1 and T2 sequences. Atypical lipomas have thick septa, are often larger in size $(>10 \mathrm{~cm})$, and have a decreased fat composition, with nodular intralesional nonfat content and septal enhancement. ${ }^{8-10}$

\section{Epidermal Cyst}

An epidermal cyst (also known as epidermoid cyst or epidermal inclusion cyst) is a cystic structure containing keratin debris bound by stratified squamous epithelium. ${ }^{11}$ The most common places for subcutaneous epidermal cysts include the scalp, face, neck, trunk, and back. ${ }^{12}$ They are commonly but incorrectly known as sebaceous cysts; "sebaceous" implies they originate from sebaceous glands, which they do not. Epidermal cysts are
License terms

() (1) $\Theta \circledast$ 


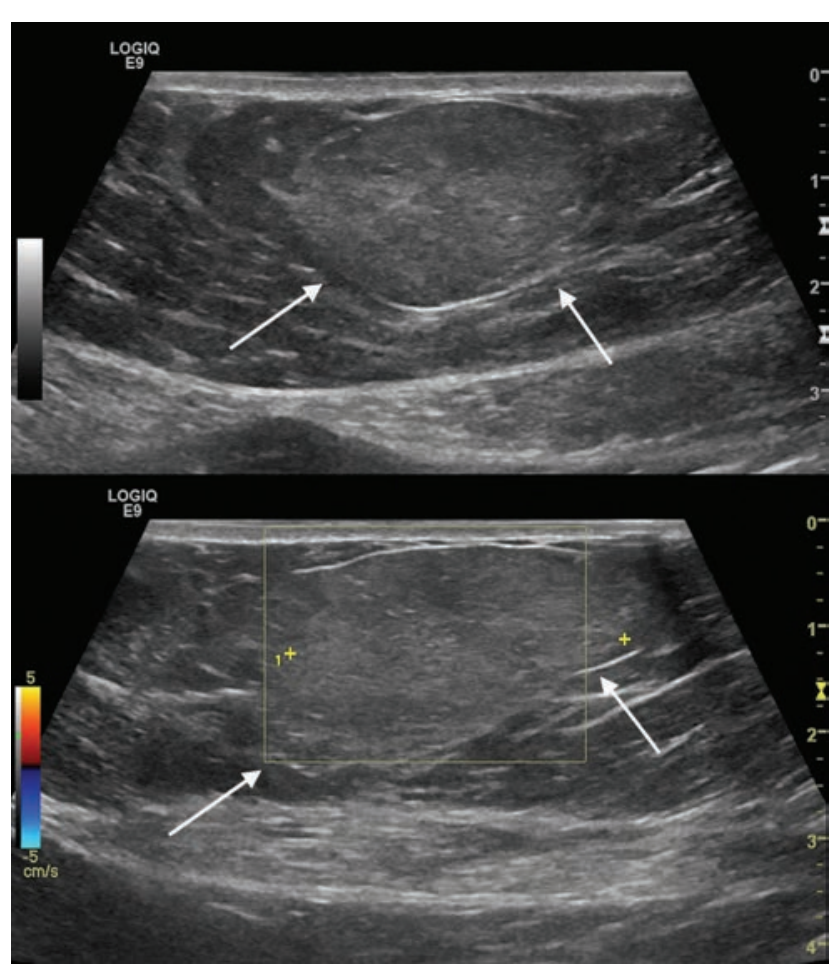

Fig. 1 Ultrasound scan (USS) of simple lipoma. Smooth epigastric, mobile mass. USS shows a small, well-defined echogenic lesion in the subcutaneous tissue with no appreciable color flow. Findings are consistent with a simple lipoma.

well-defined round or oval lesions and on USS are mostly hyperechoic with posterior acoustic enhancement. On MRI, these are usually hyperintense on $\mathrm{T} 2$ sequences, although in many cases, variable low signal components are also seen ( - Fig. 2). These have been postulated to be secondary to the heterogeneous histopathologic features of the epidermal cysts. ${ }^{13}$ Brenner et al have found intratesticular epidermal cysts to contain multiple layers of keratin debris, with dense debris in a cystic centre and intraluminal calcification. ${ }^{14}$ Differential diagnoses of epidermal cysts include ganglions and bursitis, which both demonstrate T2 hyperintensity. Hong et al (2006) felt that meticulous examination of the intralesional variable hypointensity was required to differentiate an epidermal cyst from other cystic lesions, as the enhancement pattern alone was not sufficient to differentiate lesions. ${ }^{13}$ Ruptured epidermal cysts have no change in magnetic resonance signal compared with unruptured epidermal cysts; however, they can demonstrate thick septa with thick irregular rim and adjacent soft tissue enhancement, thus mimicking an inflammatory condition such as abscess, complicated ganglion and bursitis ( - Fig. 3). Some ruptured epidermal cysts can show worrying features from the spectrum of soft tissue malignancies such as central necrosis, thereby making the diagnosis problematic on imaging alone. ${ }^{13}$

\section{Abdominal Wall Hematoma}

An abdominal wall hematoma can be divided broadly into two categories: a rectus sheath hematoma and a lateral abdominal wall hematoma, with rectus sheath hematomas the more common of the two. ${ }^{15}$ The bleeding occurs due to muscle damage or injury to the superior or inferior epigastric arteries. A rectus sheath hematoma can occur spontaneously with other attributable causes, including trauma, surgery, vigorous muscle contraction, and subcutaneous injections (-Fig. 4). Risk factors include old age, obesity, pregnancy, female sex, hypocoagulable states, and renal insufficiency. ${ }^{16-18}$

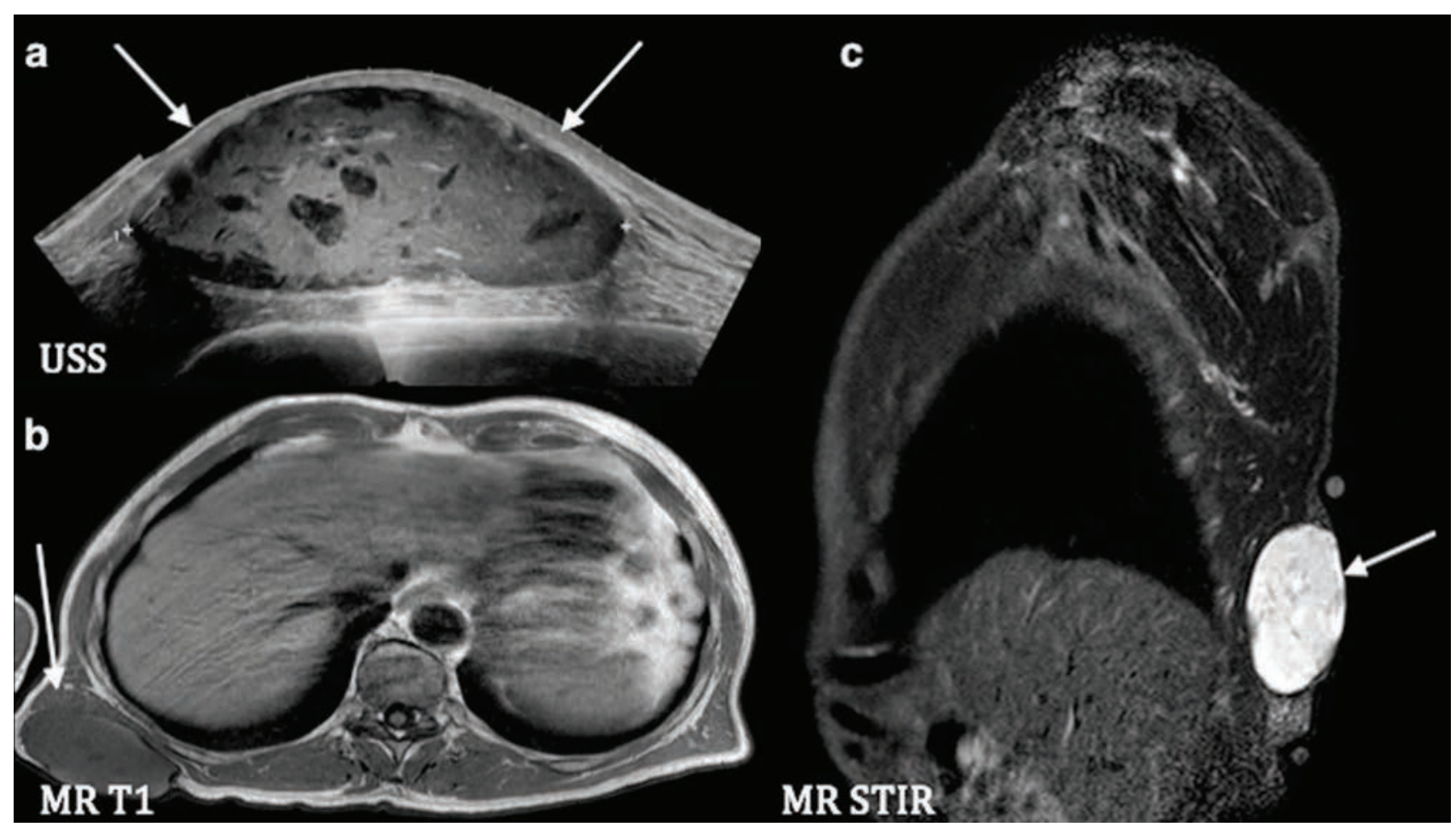

Fig. 2 Epidermal cyst. A 65-year-old man with lump in the lower back. Ultrasound scan (USS) (a) demonstrates a subcutaneous, well-defined heterogeneous mass. MRI of the same patient shows T1 hypointense (b), T2/STIR (c) hyperintense lesion with no enhancement post-contrast. 


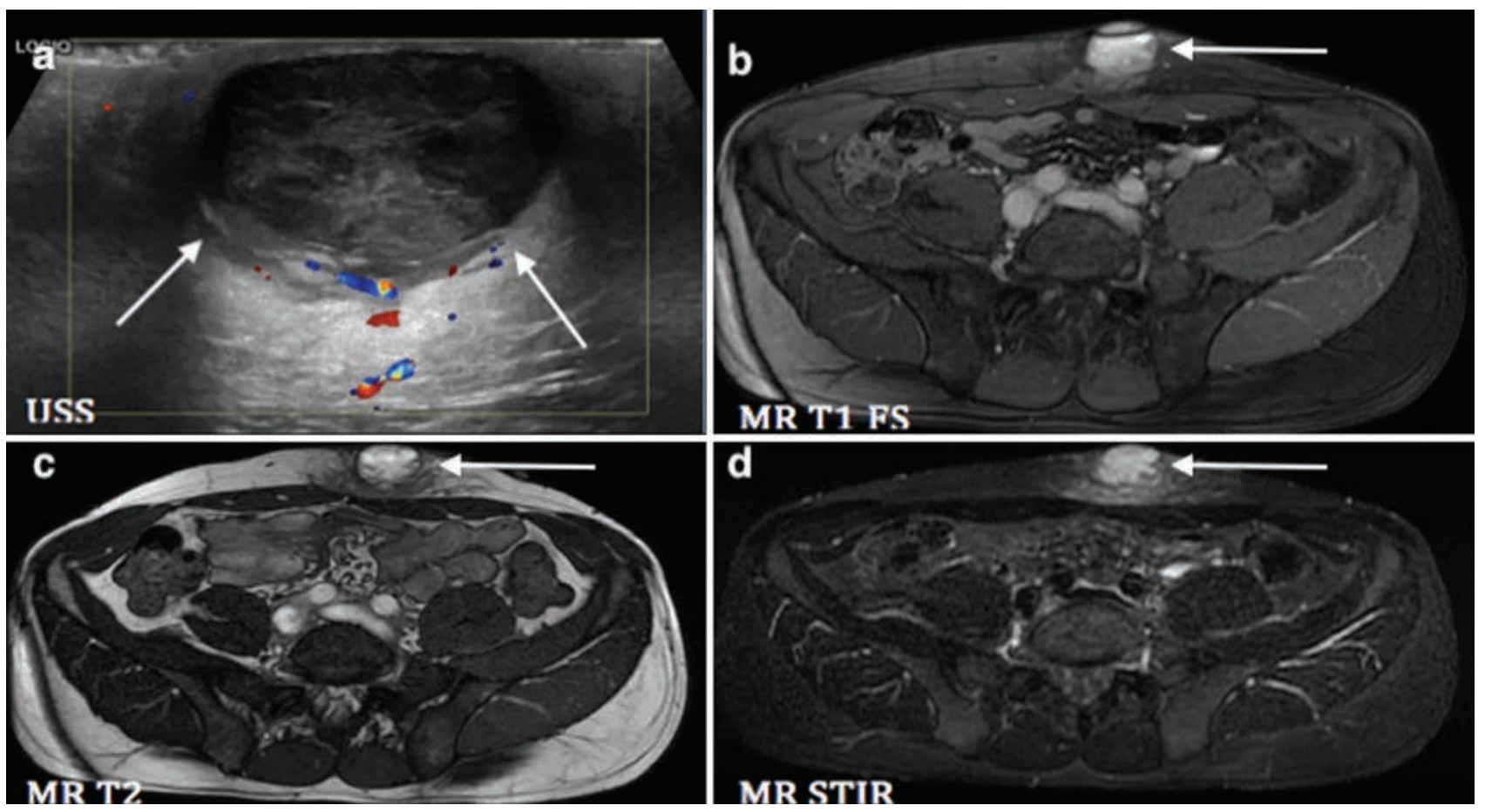

Fig. 3 Ruptured epidermal cyst. Ultrasound scan (USS) (a) shows heterogeneous subcutaneous cystic lesion with peripheral color flow in the epigastrium. MRI of the same patient shows T1 FS (b), T2 (c), and STIR (d) hyperintensity with mild inflammatory change of the surrounding fat. Histology confirmed ruptured epidermal cyst with inflammatory surrounding tissue.
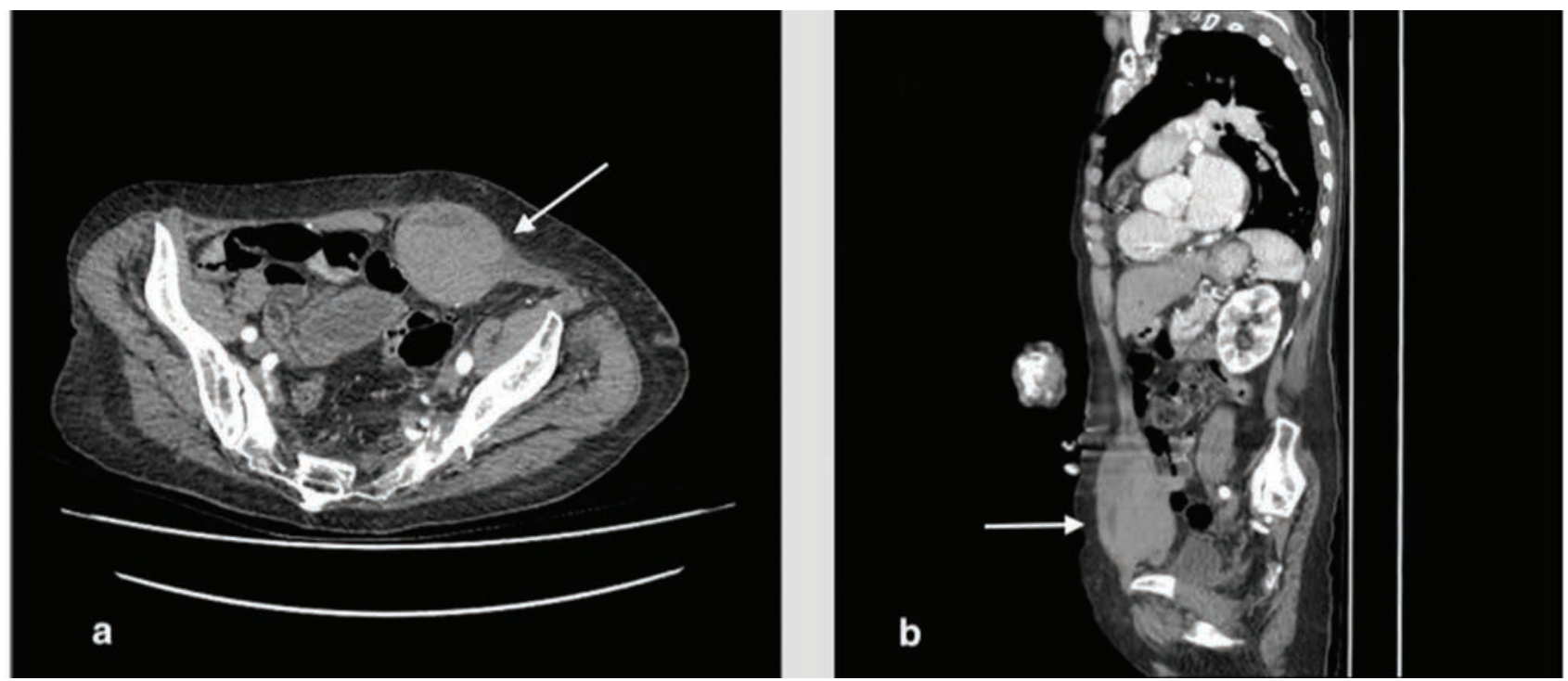

Fig. 4 Rectus sheath hematoma. Patient on warfarin presented with anterior abdominal mass and no history of trauma. Axial (a) and sagittal (b) contrastenhanced CT in the portal venous phase shows a left acute spontaneous rectus sheath hematoma that measured on average 60 Hounsfield units.

Patients may present with pain, nausea, and vomiting with a firm tender mass, often mimicking an incarcerated hernia. Ecchymosis can usually take up to 2 to 5 days to occur making early clinical diagnosis difficult. ${ }^{17}$ Lateral abdominal wall hematoma is less frequent than rectus sheath hematoma and can occur spontaneously or secondary to blunt injury. Iatrogenic hematomas are also known to occur-arising from the deep circumflex iliac artery from trocar placement during laparoscopic surgery and from a false aneurysm arising from superficial femoral artery from vascular intervention. ${ }^{19}$ CT has the advantage of having $100 \%$ sensitivity and specificity and can demonstrate active bleeding with contrast administration ${ }^{16,20}$ ( - Figs. $\mathbf{4}, \mathbf{5}$ ). If there is a concern of active hemorrhage, a triple-phase CT (unenhanced, arterial and delayed venous phase scan) is advised to identify the point of bleeding and vascular anatomy to aide intervention.

\section{Malignant Soft Tissue Lesions}

\section{Malignant Peripheral Nerve Sheath Tumors}

Neurofibromas are benign tumors associated with neurofibromatosis type 1 (NF1) that consist of Schwann cells, fibroblasts, and perineural cells. These are well-defined lesions that appear in the dermis or subcutaneous tissue. Malignant peripheral 


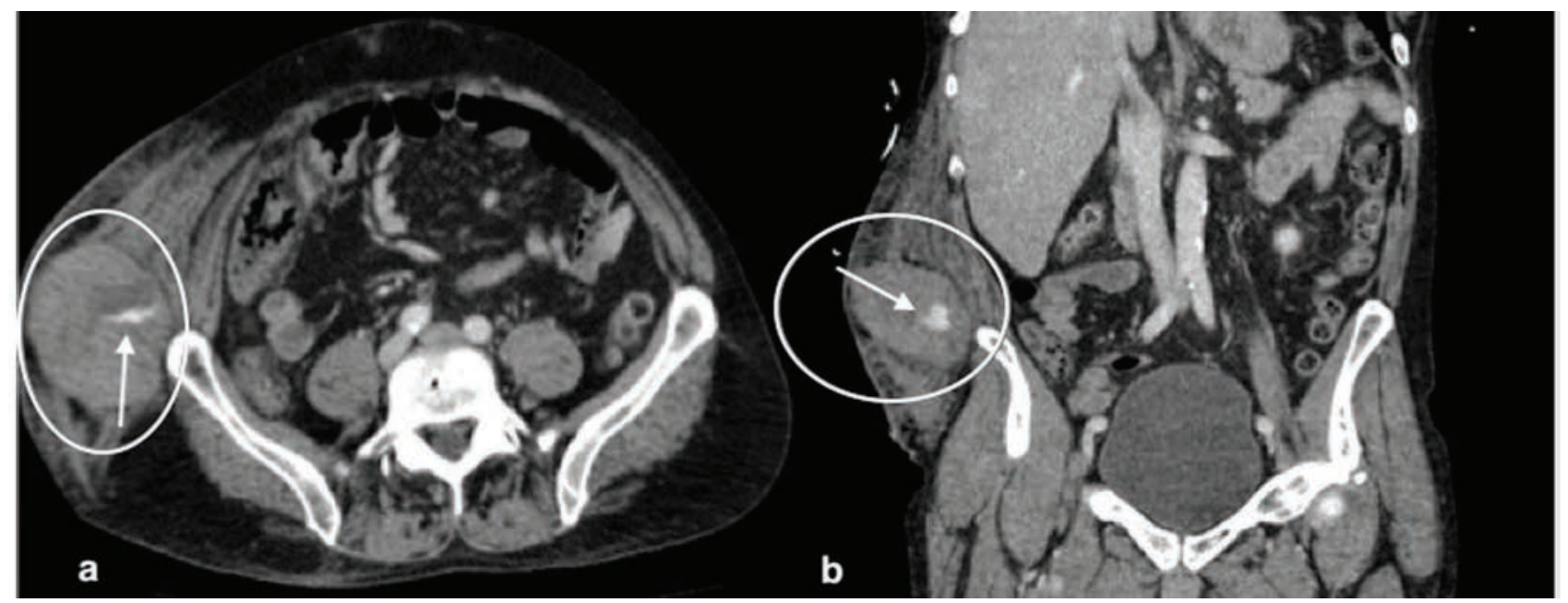

Fig. 5 Lateral abdominal wall hematoma. Blunt trauma in patient with large right-sided abdominal wall swelling. Axial (a) and coronal (b) CT scans in the venous phase shows a hematoma in the right anterolateral abdominal wall (circle) with evidence of active contrast extravasation, with contrast "pooling" on the portal venous (arrow) phase indicating active hemorrhage.
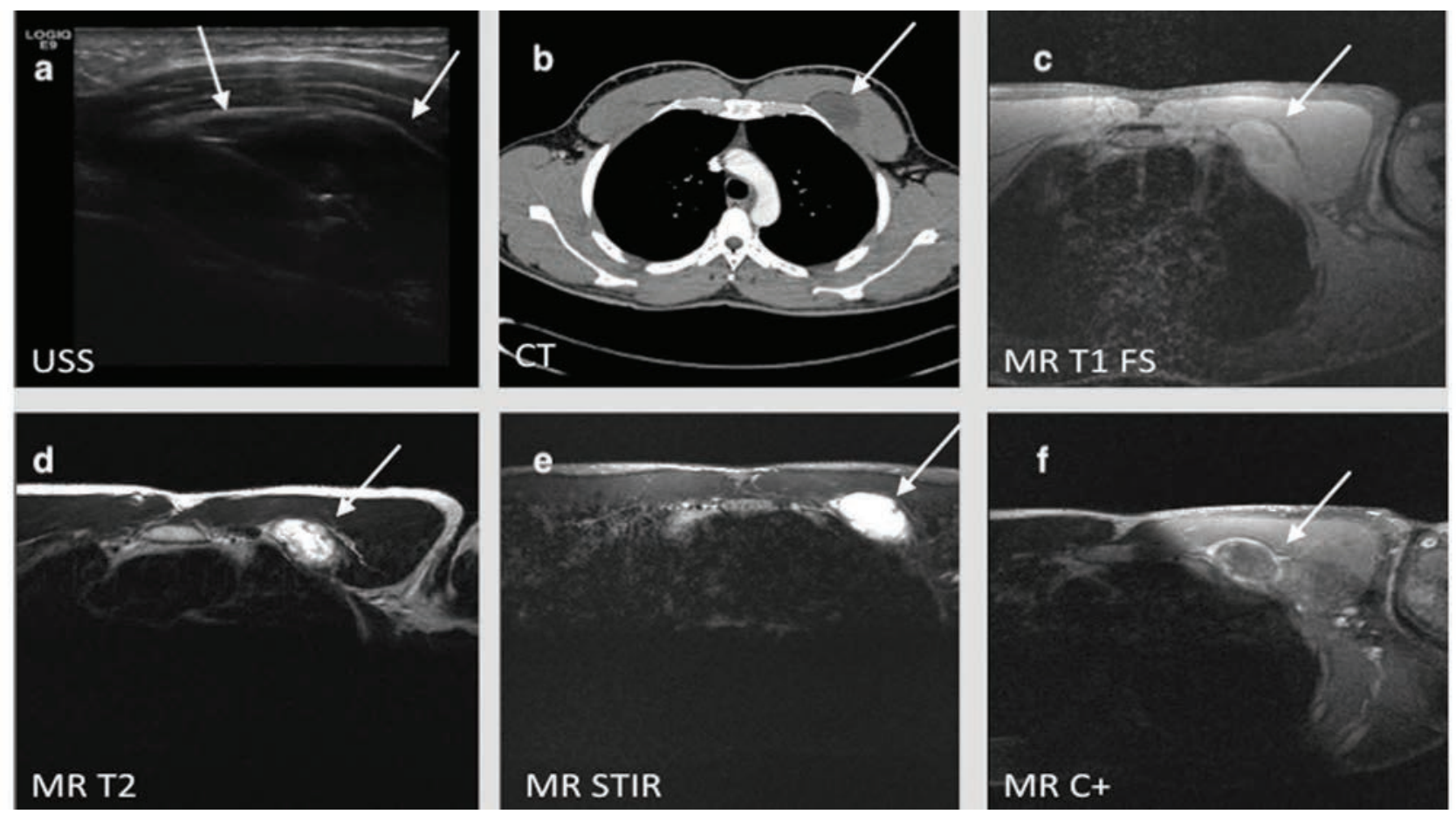

Fig. 6 Malignant peripheral nerve sheath tumor. Patient presented with 4 months history of painless left upper quadrant/lower chest mass. Ultrasound scan (USS) (a) with a biopsy needle in situ demonstrates a hypoechoic, well-delineated deep submuscular lesion. A venous phase axial CT scan (b) reveals a well-circumscribed hypoattenuating ovoid lesion with no significant enhancement underlying the pectoral muscles on the left side of the lower chest (arrow). The same lesion is isointense on axial T1WI fat saturated (c), heterogeneously hyperintense on axial T2WI (d), and STIR (e) (arrows). It demonstrates peripheral contrast enhancement on the post-contrast MRI (f). Histology confirmed MPNST.

nerve sheath tumors (MPNST) also known in the literature as malignant schwannoma, neurogenic sarcoma, and neurofibrosarcoma occur more often in the deep soft tissues closer to the nerve trunks, such as the sciatic nerve and brachial and sacral plexus. ${ }^{21}$ MPNST is distinguished from a typical neurofibroma by the presence of mitotic features. ${ }^{21}$ Approximately 40 to $60 \%$ of MPNSTs arise in NF1 patients, and MPNST accounts for $10 \%$ of all soft tissue sarcomas. ${ }^{22}$ MPNST patients classically present with pain or focal neurologic deficit along the nerve that is affected due to impingement or mass effect. ${ }^{23}$ Radiologically, MPNST is usually low attenuating on CT due to the fat content of myelin from Schwann cells or the high water content of myxoid tissue. ${ }^{24}$ USS demonstrates a hypoechoic, well-defined mass lesion. Magnetic resonance characteristics of MPNST are relatively nonspecific and are usually isointense to muscle on T1-weighted images and hyperintense on T2-weighted sequences. A rim of fat ("split-fat sign") can be present as the neurovascular bundle is normally surrounded by fat. MPNST is also found to be more 

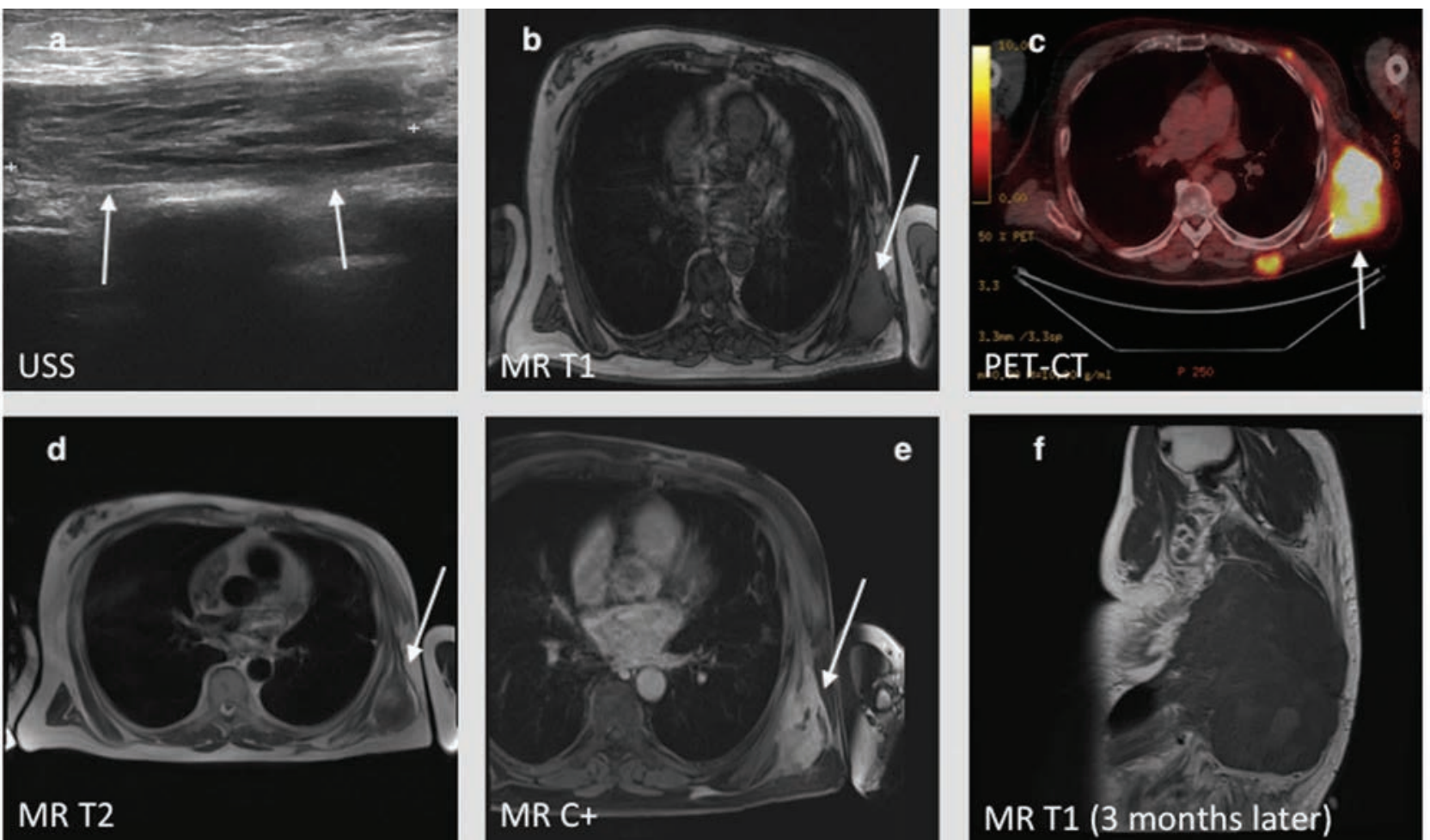

\section{MR T2}

Fig. 7 Leiomyosarcoma. Patient presented with a mass in the left lower chest/upper lumbar region. Ultrasound scan (USS) (a) shows an ill-defined heterogeneous lesion within the muscular layer marked within cursors. MRI of the same patient demonstrates the mass marked by arrow with hypointensity on axial T1WI (b), isointensity on axial T2WI (d) that enhances in the axial post-contrast (e) and shows avid uptake on PET-CT. (c) A follow-up sagittal T1WI MRI 3 months later shows rapid increase in size (f). Histology confirmed the suspicion of a leiomyosarcoma.
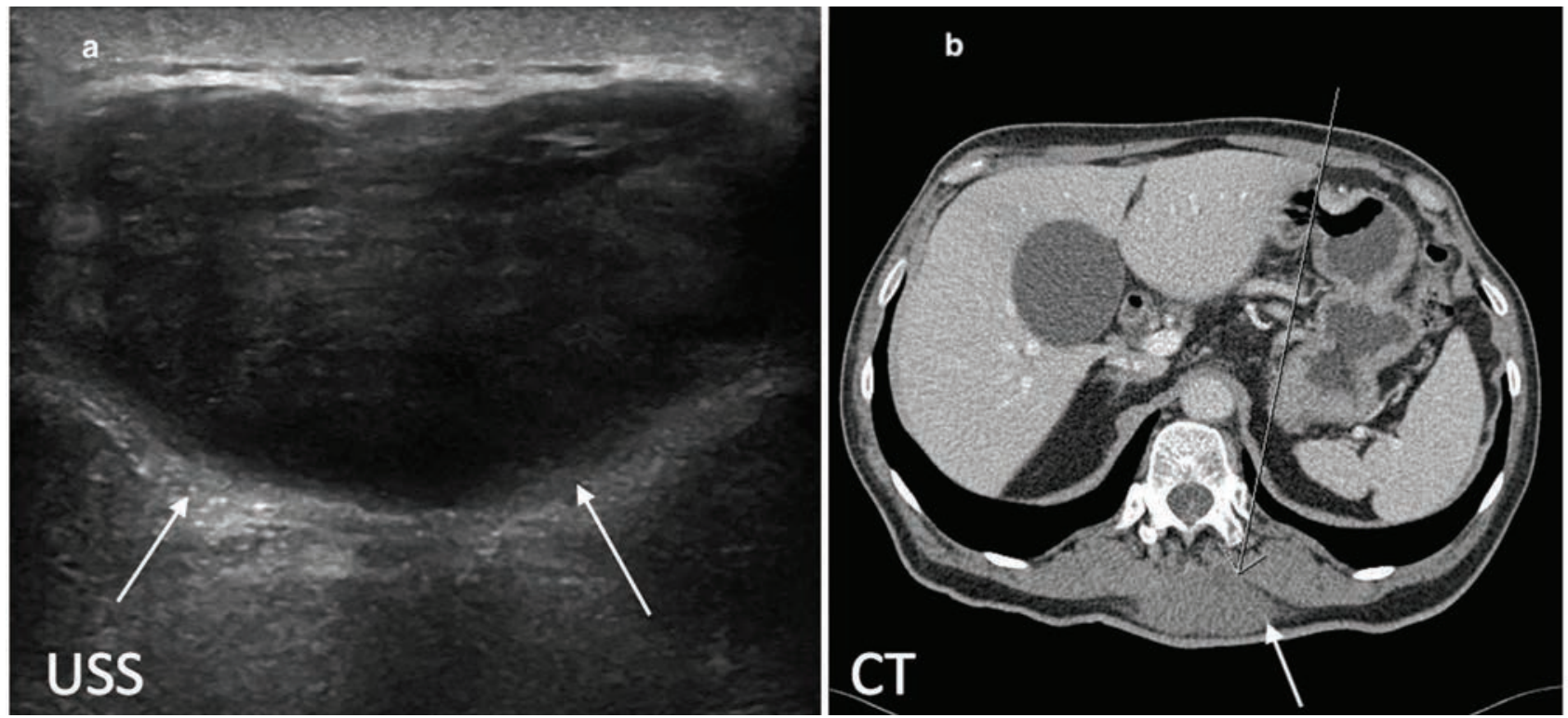

Fig. 8 Pleomorphic sarcoma. Ultrasound scan (USS) (a) demonstrates a hypoechoic, well-circumscribed, smoothly surfaced solid mass in the left thoracolumbar junction overlying the paraspinal muscles. Axial post-contrast CT in venous phase (b) shows a discrete mass in the subcutaneous plane in the midline without extension into the paraspinal muscles (arrow). Histology confirmed pleomorphic undifferentiated sarcoma.

heterogeneous compared with other neurogenic tumors. Contrast enhancement is also variable in both benign and malignant peripheral nerve sheath tumors, although contrast enhancement is more apparent in MPNST $^{24}$ (-Fig. 6).

\section{Sarcoma}

Sarcoma arises from mesenchymal cells; thus, malignancy of the cancellous bone, cartilage, fat, muscle, vasculature, and hematopoietic tissue are broadly categorized as being sarcomas. They account for approximately $1 \%$ of adult solid tumors, frequently affecting those between the fourth and sixth decades of life with a 2:1 male predilection. ${ }^{25}$ There are two histologic groups that involve the abdominal wall: desmoid tumors (low-grade nonmetastasizing fibrosarcoma) and fully malignant soft tissue sarcomas (rhabdomyosarcoma, fibrosarcoma, leiomyosarcoma, liposarcoma, synovial sarcoma, and 


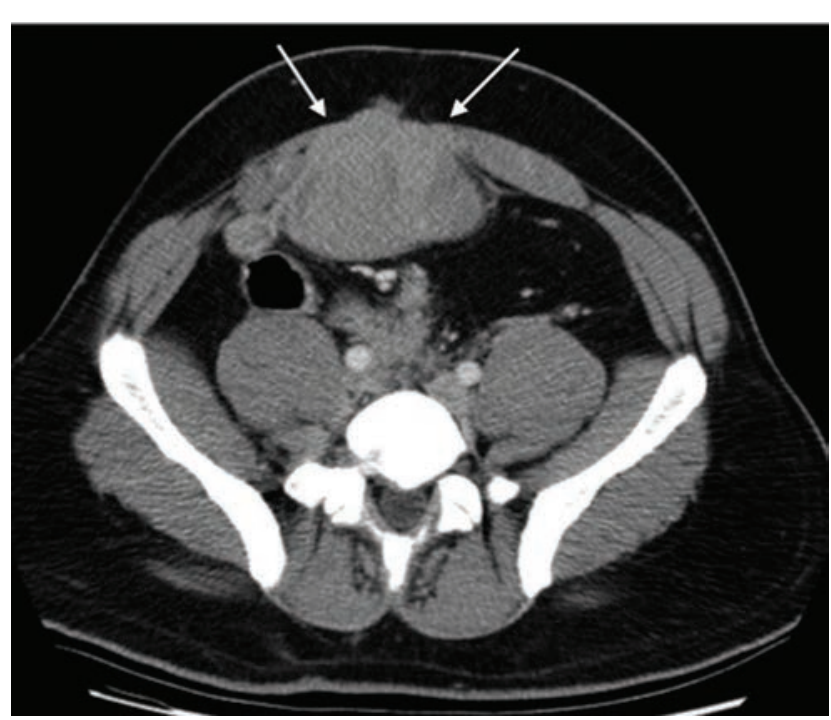

Fig. 9 Desmoid tumor of the abdominal wall shows heterogenous attenuation with variable enhancement on axial post-contrast $C T$ in the venous phase (arrow). This lesion should not be confusedwith a rectus sheath hematoma as the epicenter of the lesion is not the rectus muscle within the rectus sheath but on either side of the inner rectus sheath (see $\boldsymbol{-}$ Fig. $\mathbf{4}$ for comparison). malignant fibrous histiocytoma) with potential for metastases. The imaging appearance of the fully malignant sarcomas will vary depending on the type of tissues that make up the tumor (-Figs. 7, 8). These usually grow rapidly, recur, and often metastasize making prognosis poor. Full-thickness abdominal wall resection with adjuvant chemotherapy is used to prevent distant disease. ${ }^{26}$

\section{Desmoid Tumor}

Desmoid tumors, also known as aggressive fibromatosis, consist of spindle cells of uniform appearance surrounded by collagen. ${ }^{27}$ These are slow-growing tumors with no metastatic tendency, although death can occur due to local mass effect (-Fig. 9). Prognosis is good, although local recurrence can occur with inadequate resection. ${ }^{26}$ USS is useful in evaluating desmoid tumors, which are well defined with varying degrees of echogenicity. ${ }^{28}$ CT and MRI are useful tools to evaluate the size, site, extent, and relationship of the lesion to the surrounding structures. Desmoid tumors have nonspecific appearance on CT and can therefore be hypo-, iso-, and hyperattenuating compared with muscle with varying degree of enhancement post-contrast $^{29}$ (-Fig. 10). MRI shows similar characteristics,
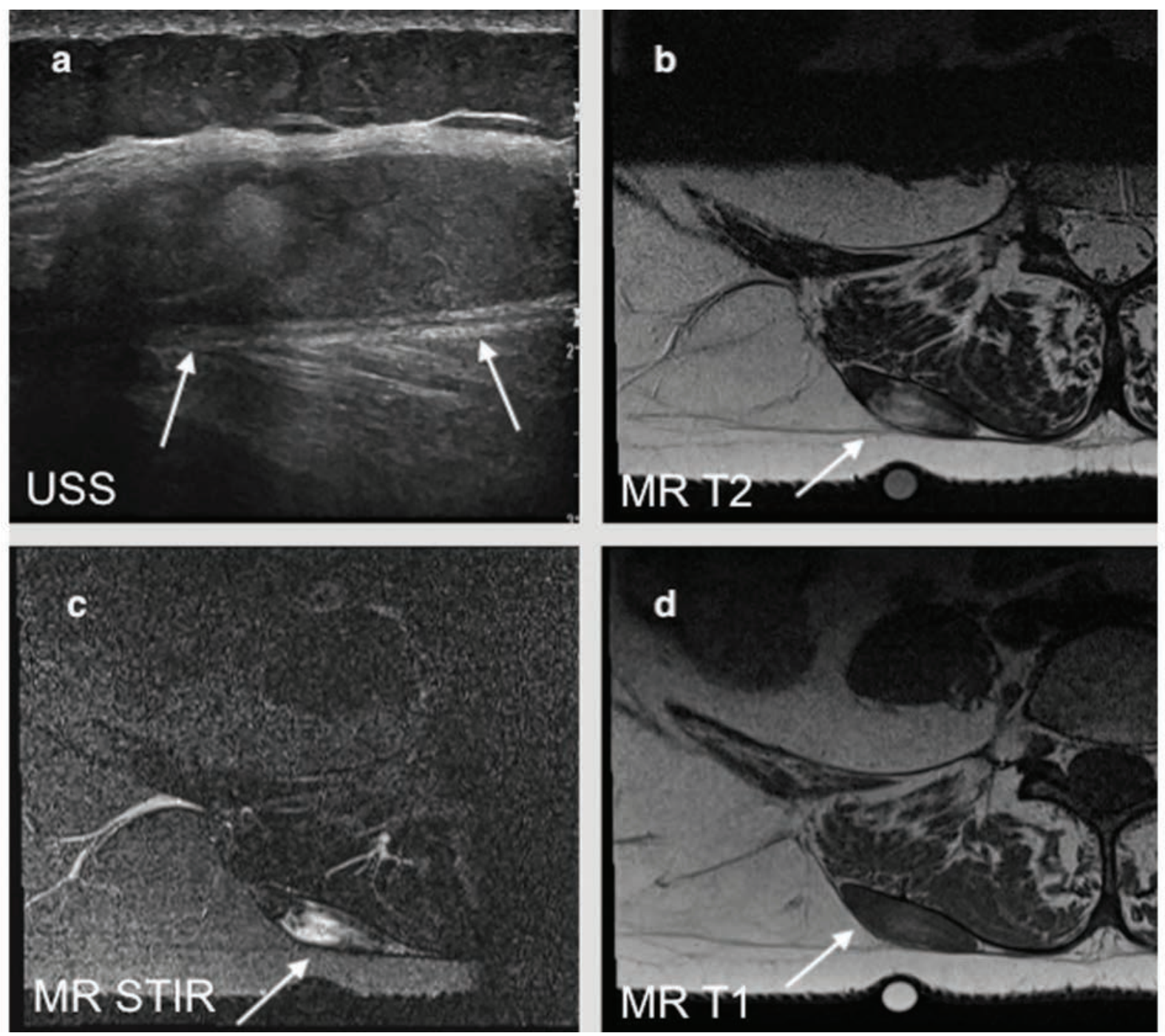

Fig. 10 Desmoid tumor. Ultrasound scan (USS) (a) reveals a mixed echogenic mass in the right lower back (arrows), which on MRI shows heterogenous signal intensity on T2WI (b), STIR (c), and T1WI (d). Histology confirmed spindle cell fibromatosis, desmoid tumor. 

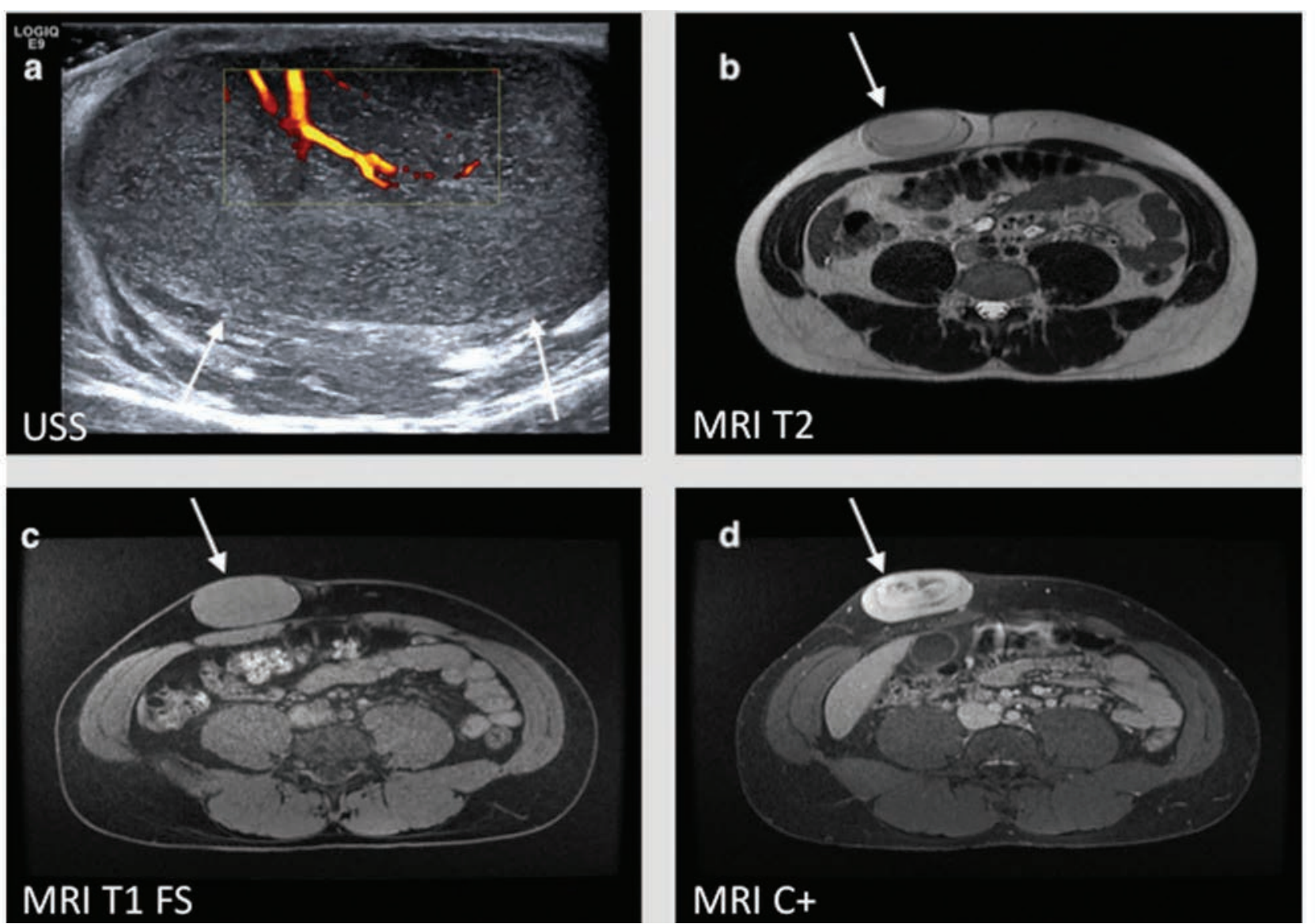

Fig. 11 Solitary fibrous tumor. Ultrasound scan (USS) (a) shows a well-circumscribed ovoid smoothly surfaced mass within the right ventral abdominal wall in the subcutaneous plane. There is a feeding vessel within the lesion on Doppler. MRI shows isointensity on T2WI (b) and T1WI FS (c) with intense contrast enhancement (d). Histology confirmed solitary fibrous tumor.

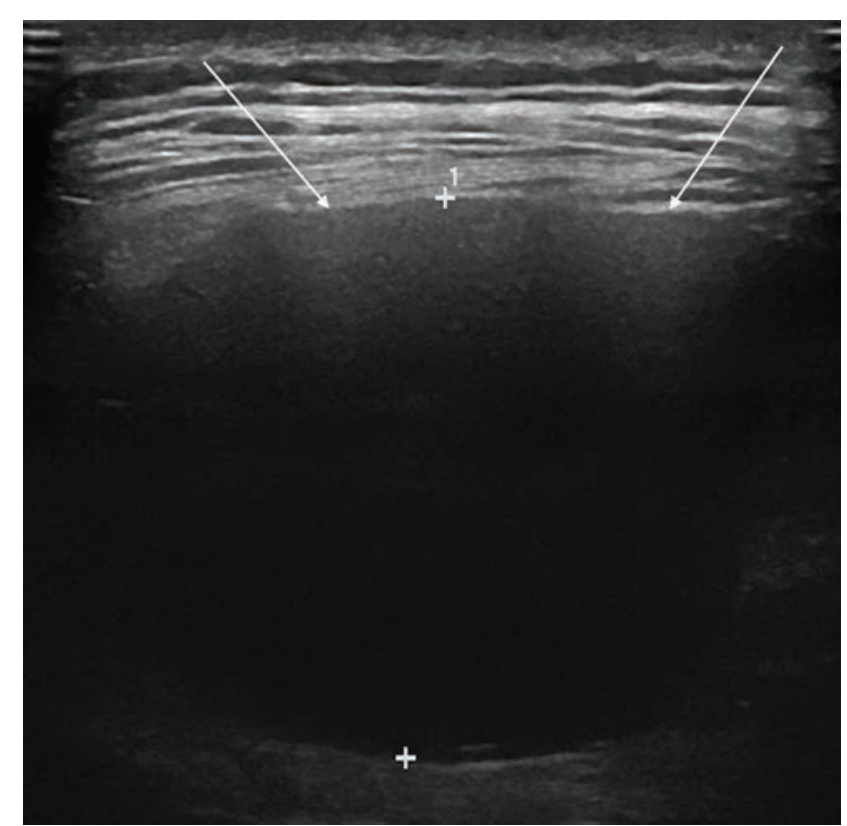

Fig. 12 Subcutaneous metastasis. There is a hypoechoic mass in the left lumbar region on ultrasound scan (USS) at the region of interest, within the paraspinal muscles. An MRI was organized to further characterize the lesion (-Fig. 13).

depending on the stage of evolution of the tumor. Three stages have been described: The first stage is mostly cellular with large extracellular space; the second stage demonstrates increased collagen deposition; and the third stage has increased fibrous composition with reduced cellularity. ${ }^{27}$ Magnetic resonance signal thus reflects the changes in each stage, with the first stage showing $\mathrm{T} 1$ low signal and $\mathrm{T} 2$ high signal. The second stage demonstrates heterogeneous signal on the T2-weighted imaging, whereas the third stage has T1 and T2 low signal due to the fibrous nature of the desmoid tumour ${ }^{27}$ ( $\mathbf{- F i g . 1 0}$ ). Because of the nonspecific appearance of desmoid tumors, definitive diagnosis is only obtained via histologic analysis.

\section{Solitary Fibrous Tumor}

Solitary fibrous tumor is a rare mesenchymal tumor that comprises less than $2 \%$ of all soft tissue tumours. ${ }^{30}$ Although most solitary fibrous tumors are benign, up to $10 \%$ can become locally aggressive with distant metastasis. ${ }^{31,32}$ USS shows a hypoechoic lesion with areas of heterogeneous echotexture representing myxoid degeneration. CT demonstrates a well-circumscribed, lobulated mass, which may contain scattered calcification. ${ }^{33,34}$ MRI features are nonspecific; however, most cases show variable signal intensity on T2-weighted imaging and isointensity on T1 imaging (-Fig. 11). Areas of low signal intensity in both T1 and T2 sequences represent collagen content with low cellularity. ${ }^{35}$ Solitary fibrous tumors are a hypervascular neoplasm that demonstrates intense contrast enhancement. However, 
because of marked variability in its pattern of enhancement, heterogeneous enhancement is not an indicator of malignant degeneration. ${ }^{35} \mathrm{~A}$ solitary fibrous tumor larger than $10 \mathrm{~cm}$ generally has an unfavorable outcome with increased risk of local recurrence and distant metastasis. ${ }^{34}$

\section{Cutaneous and Abdominal Wall (within Muscles) Manifestations of Malignancy}

Subcutaneous metastases are extremely rare even though soft tissues account for almost $40 \%$ of total body weight. ${ }^{36}$ Because of prevalence alone, the most common subcutaneous metastasis is from breast cancer in women, whereas malignant melanoma followed by lung cancer is the most common cause in men. ${ }^{37}$ Subcutaneous nodules are found in almost $30 \%$ of patients with malignant melanoma (predominantly those with Clark IV and V disease). ${ }^{38}$

It is important to differentiate primary soft tissue sarcoma and metastases early due to differences in their treatment and prognosis. Although there are similarities, extensive peritumoral enhancement associated with central necrosis is thought to be a characteristic feature of skeletal muscle metastasis ${ }^{39}$ (-Figs. 12, 13). Although these findings are nonspecific in subcutaneous metastasis, early radiologic investigation should be sought to help differentiate it from primary $\operatorname{sarcoma~}^{40}$ ( - Fig. 14).
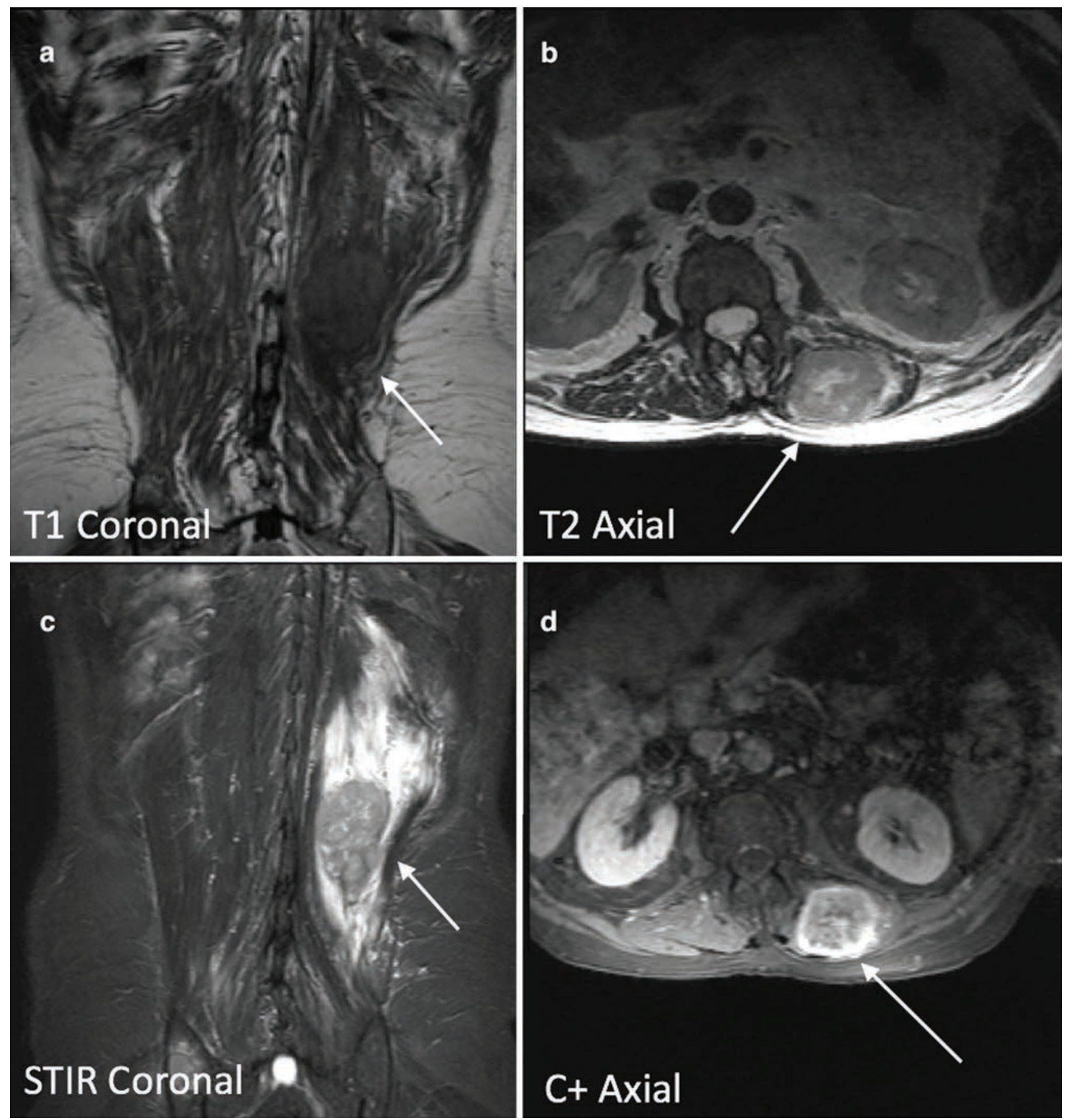

Fig. 13 Deep, intramuscular mass. Subsequent MRI shows a heterogeneous lesion with central necrosis low signal on T1WI (a) and high central signal on T2WI and STIR (b, c). There is extensive perilesional soft tissue edema on STIR (c) and variable contrast enhancement (d). Histology confirmed metastatic adenocarcinoma from lung primary. 

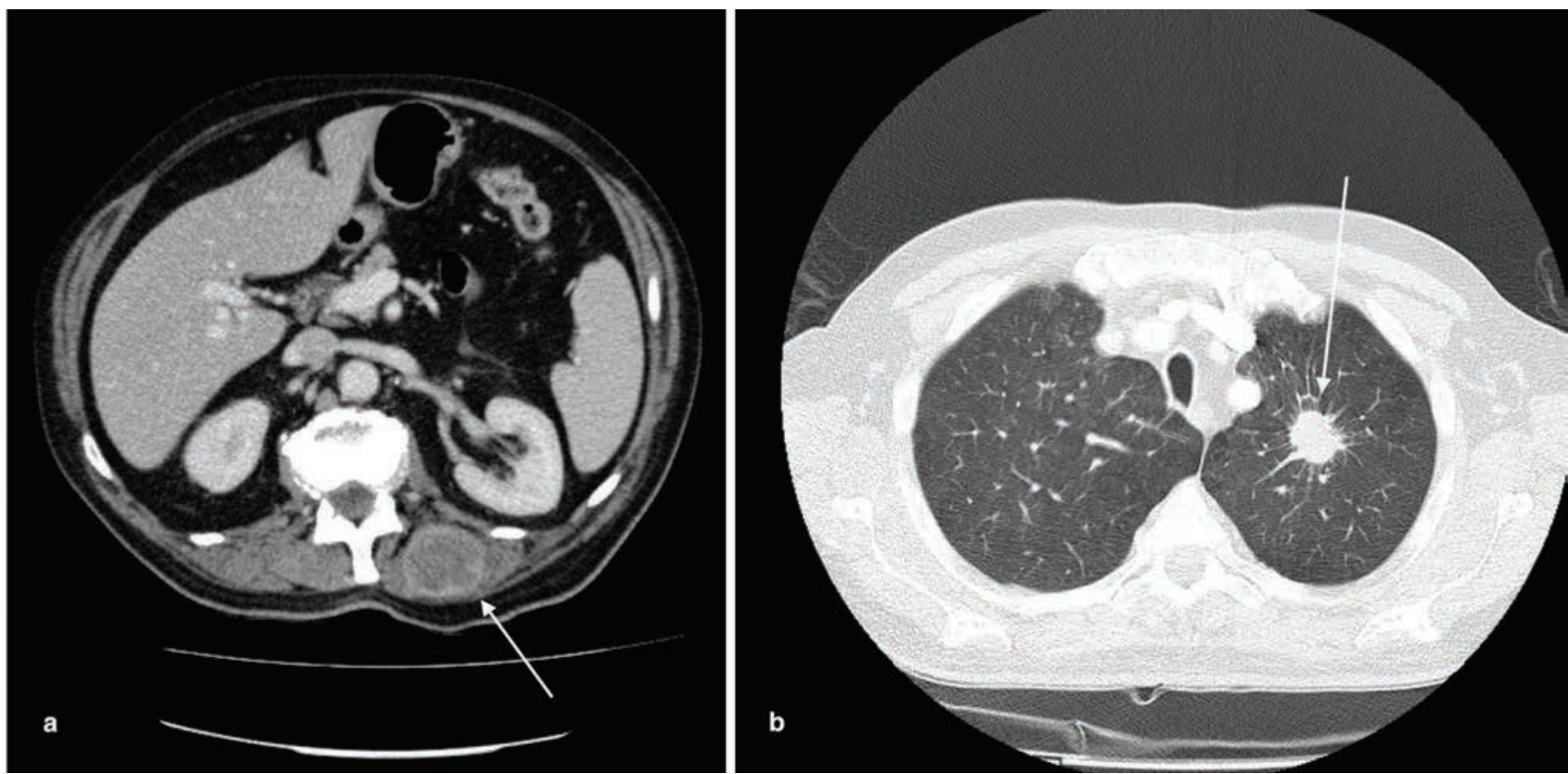

Fig. 14 Deep, intramuscular mass. Axial portal venous phase CT (a) shows a left parapineal muscle irregular rim-enhancing necrotic lesion. Biopsy was performed with histology confirming metastatic adenocarcinoma. Staging CT axial of chest (b) reveals metastatic lung carcinoma (arrow).
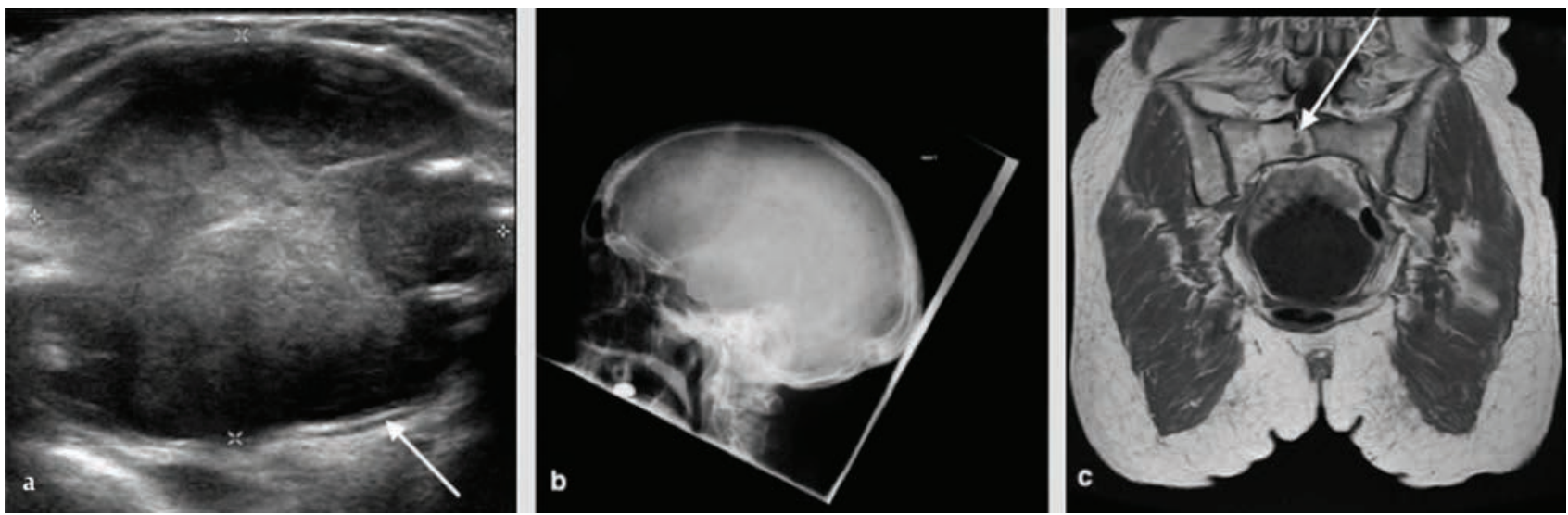

Fig. 15 Myeloma mark lesion with short arrow in each. Patient with epigastric mass. Ultrasound scan (USS) (a) shows large subcutaneous echogenic mass at the level of the epigastrium. Subsequent skeletal survey (b) and MRI (c) shows multiple lytic bone lesions in keeping with multiple myeloma.

\section{Myeloma}

Multiple myeloma is hematologic malignancy involving the bone marrow plasma cells. Extraosseous myeloma is uncommon and found in less than $5 \%$ of patients with multiple myeloma, being associated with an aggressive form of the disease process. ${ }^{41}$ Radiologic findings are not specific, often demonstrating a homogenous well-defined subcutaneous mass that can mimic lymphoma, sarcoma, metastases, or a desmoid tumor ( - Fig. 15). In a patient with a known history of multiple myeloma, biopsy of the soft tissue mass should be performed to confirm the diagnosis.

\section{Lymphoma}

Lymphomas are broadly categorized as Hodgkin lymphoma (HL) and non-Hodgkin lymphoma (NHL), which comprise $5 \%$ and $6 \%$ of all malignancies, respectively. ${ }^{42}$ Lymphomas affect nodal and extranodal structures of the abdomen and pelvis. ${ }^{43,44}$ The manifestation of a lump in the abdominal wall is usually due to a nodal disease, but it may rarely affect the muscle, subcutaneous fat, or skin separate from hematogenous spread. ${ }^{44}$ Nodal disease is either solitary or more commonly multiple, where an enlarged mass can represent a solitary lymph node or a conglomerate of enlarged adjacent lymph nodes. On USS, nodes are found along the typical nodal chains, characteristically showing an enlarged, hypoechoic node greater than $1 \mathrm{~cm}$ in the short axis ( - Fig. 16). CT shows enlarged round or lobular mass lesions, which demonstrate homogenous enhancement. MRI is usually hypo/isointense on T1-weighted images and hyperintense on T2-weighted images ( - Fig. 17). FDG positron emission tomography (PET) imaging is important in both staging and follow-up of nodal and extranodal lymphomas, as PET is superior to $\mathrm{CT}$ at detecting extranodal disease of the abdomen ${ }^{43,45,46}$ ( - Fig. 18). 


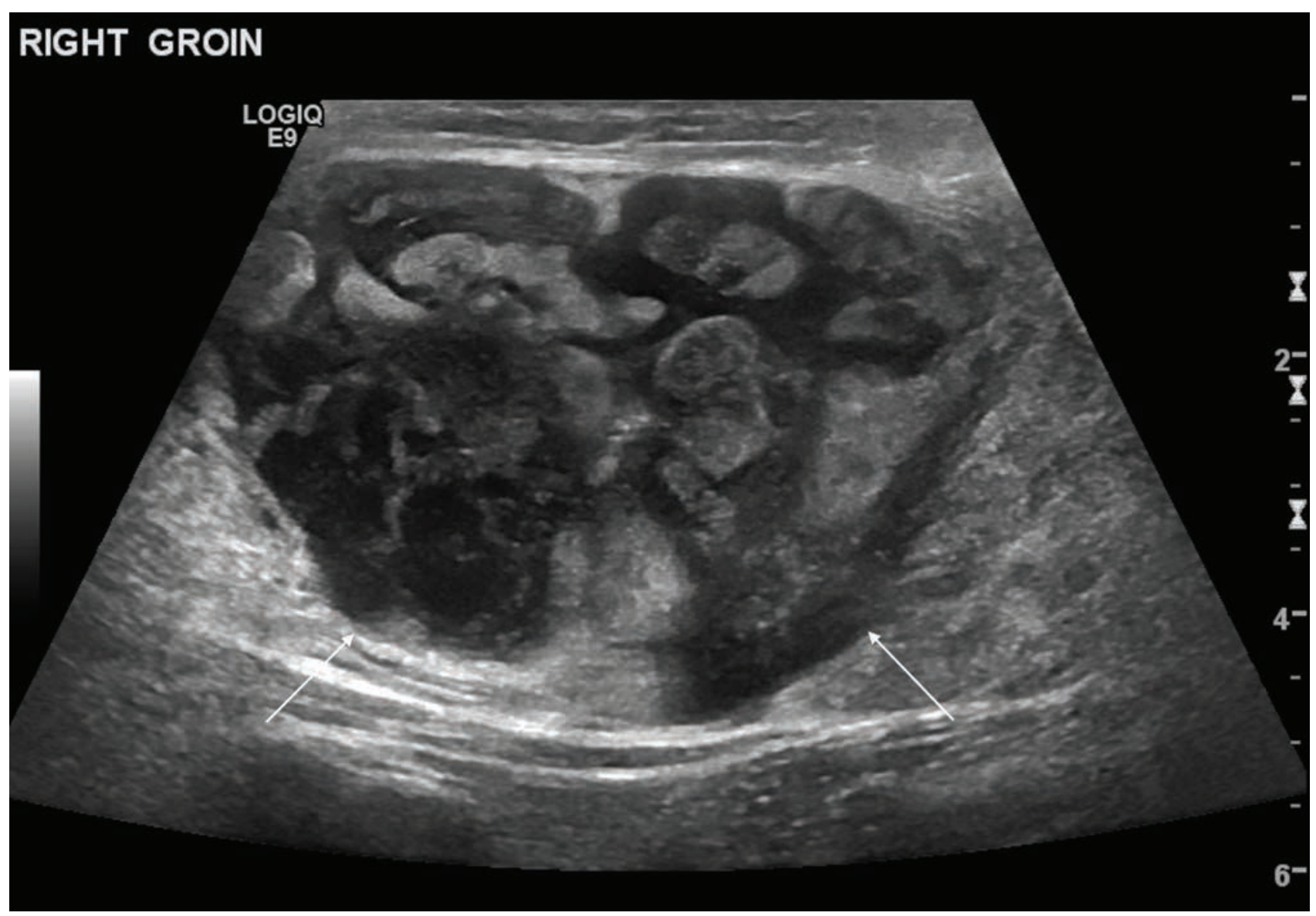

Fig. 16 Diffuse large B-cell lymphoma. Patient with right groin swelling. Ultrasound scan (USS) of right groin shows a large lobulated heterogenous soft tissue mass.

\section{Miscellaneous}

\section{Endometrioma}

Endometriosis of the abdominal wall has been found in procedure-related scars as well as skin, subcutaneous tissue, and the surrounding musculature. ${ }^{36}$ These commonly develop after caesarian section or hysterectomy, and it has been thought that it is secondary to dissemination of endometrial cells to the abdominal wall at the time of the surgery..$^{47,48}$ The appearance of abdominal wall endometrioma is variable on USS, CT, and MRI. It largely depends on the phase of the patient's menstrual cycle, chronicity, number of stromal and glandular cells, and the amount of associated bleeding and inflammation. ${ }^{49}$ On USS, endometriomas appear as a solid, heterogeneous, hypoechoic mass with echogenic foci and thick strands consistent with fibrosis. The degree of echogenicity will depend on the hemorrhagic versus fibrotic content. ${ }^{49,50}$ The appearance is highly variable on $\mathrm{CT}$, often hyperattenuating when compared with the adjacent muscle and demonstrating mild to moderate enhancement post-contrast. ${ }^{51}$ The appearance of endometrioma on MRI will also vary depending on the degree and age of the hemorrhagic component ( - Fig. 19). During acute hemorrhage, endometriomas are hyperintense on T1-weighted imaging, which do not suppress on fat suppression sequences. In chronic hemorrhage, it is usually hypointense on T2WI. It can show variable amount of diffusion weight restriction and contrast enhancement.

\section{Sarcoidosis}

Sarcoidosis is a systemic inflammatory condition of unknown origin characterized by the hallmark feature of noncaseating granulomas. Although pulmonary changes are the most frequent finding, sarcoidosis can affect anywhere in the body, including the abdominal wall. ${ }^{52}$ Sarcoidosis can have three distinctive appearances including nodular, myopathic, or myositic forms when skeletal muscle is involved. The nodular form can extend along the muscle fibers, whereas the myopathic form is characterized by muscle atrophy and fatty infiltration ${ }^{53}$ ( - Fig. 20). There is pseudohypertrophy of the muscle bulk, due to fatty infiltration despite muscle atrophy. Abdominal involvement in sarcoidosis usually coincides with more extensive thoracic disease, although isolated abdominal cases are not rare. ${ }^{52}$ Imaging findings are of nodular infiltration within the muscle layer with pseudohypertrophy of the muscle with fat infiltration. Increased FDG uptake has been reported in sarcoidosis as well as other granulomatous infections. Involvement of multiple abdominal visceral organs such as the liver, spleen, lymph nodes, muscle, skin, and subcutaneous tissue can thus be mistaken for infection and disseminated neoplasm, such as lymphoma. ${ }^{54}$

\section{Undescended Testis}

Cryptorchidism or undescended testes is the most common genitourinary anomaly in male infants..$^{55}$ The testes 


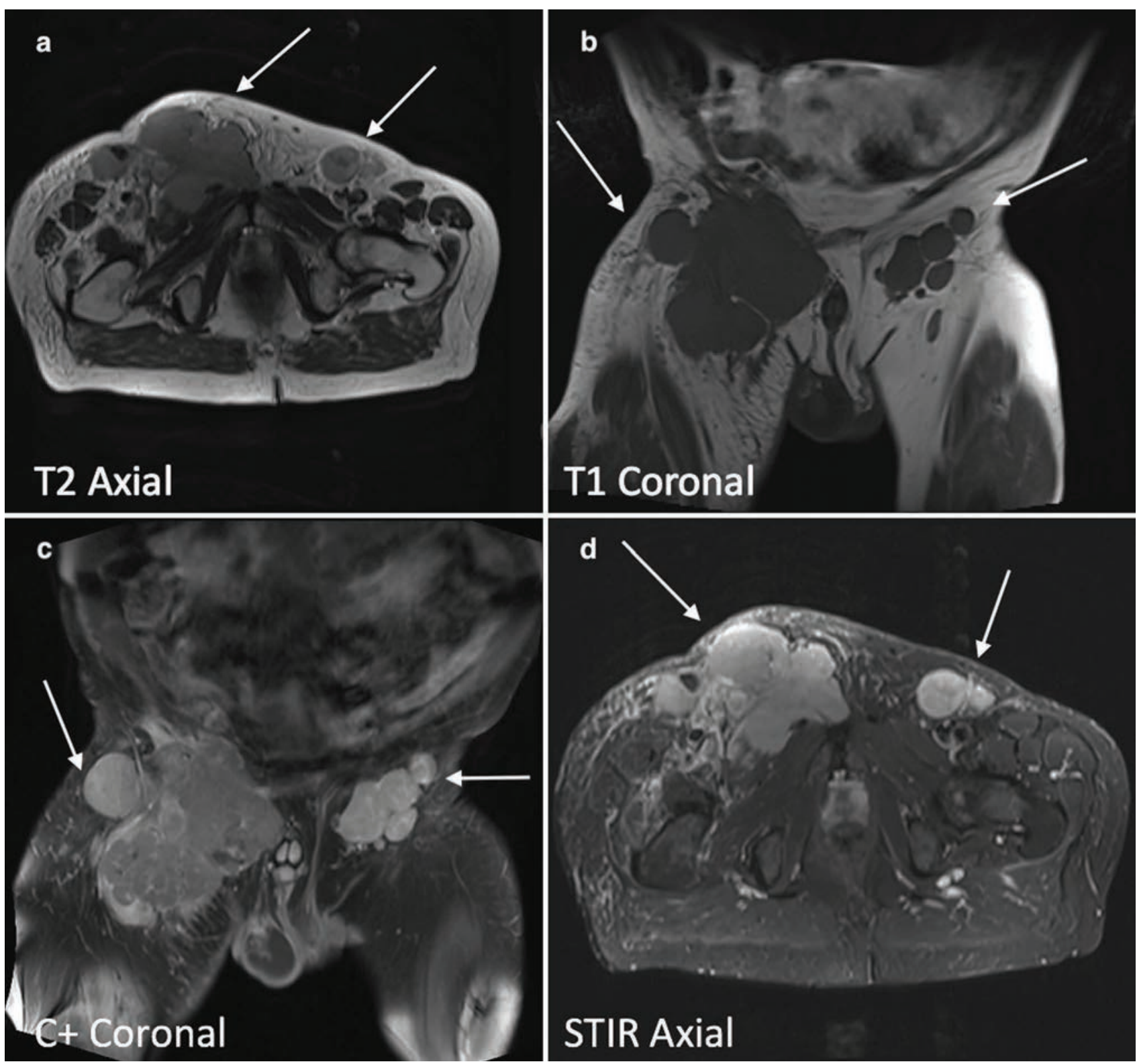

Fig. 17 Diffuse large B-cell lymphoma. MRI of the same patient in - Fig. 16 shows the mass lesion to be conglomerate of enlarged lymph nodes. They are hyperintense on T2WI and STIR (a, d) and hypointense on T1WI (b) with homogenous solid enhancement post-contrast (c). Left inguinal lymphadenopathy is also demonstrated.

develop in the abdomen at 21 weeks of gestation. Under the hormonal influence, the gubernaculum-a ligament connecting the testes to the scrotum contracts-causes the testes to descend via the inguinal canal. Premature birth, intrauterine growth restriction (IUGR), androgen insensitivity syndrome, and various congenital syndromes are thought to be causative factors for cryptorchidism. USS is commonly used as an initial imaging tool with estimated sensitivity and specificity of $45 \%$ and $78 \%$, respectively, of accurately localizing nonpalpable testes. ${ }^{55}$ Undescended testes are homogenously hypoechoic and ovoid in shape with the echogenic mediastinum of testes located centrally. USS is limited in its ability to detect intraabdominal cryptorchidism or to differentiate between an atrophic testis to an inguinal lymph node ${ }^{56}$ (-Fig. 21). MRI has mostly replaced CT as the imaging modality of choice with sensitivity and specificity of $90 \%$ and $100 \%$, respectively. ${ }^{57}$ Coronal T1 weight images are useful in detecting intraabdominal testes as well as identifying the gubernaculum to locate the undescended testes. Diffusion-weighted imaging (DWI) has also been used to accurately differentiate the undescended testes, which is hyperintense, from surrounding structures. ${ }^{58}$

\section{Conclusion}

Abdominal hernias are part of a wide range of abdominal lumps and bumps that present with nonspecific features and can be challenging for radiologists to provide a single diagnosis. Radiologists must therefore be aware that a simple abdominal wall lesion may represent a number of pathologies.

As we have described, abdominal wall lesions can lie within a spectrum of benign and malignant causes. Various 


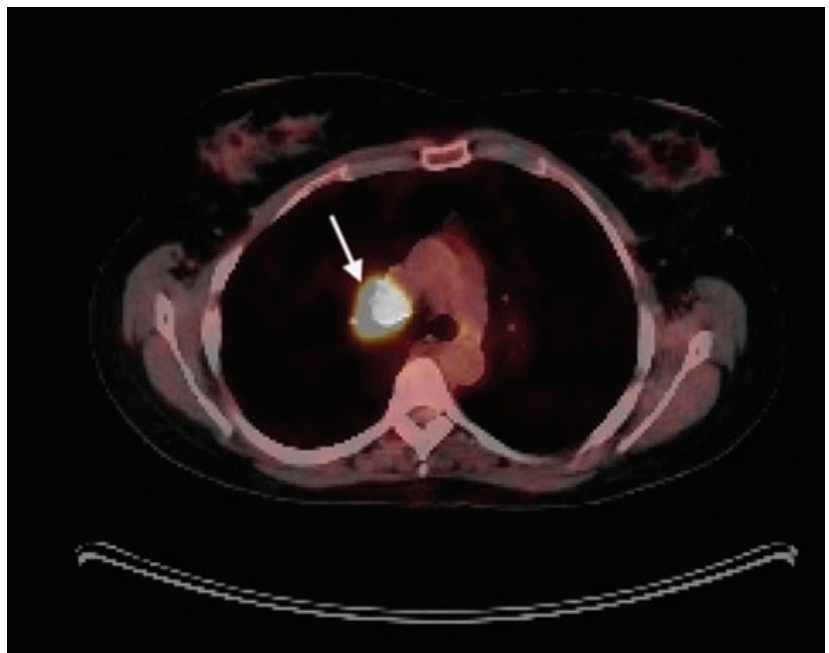

Fig. 18 Diffuse large B-cell lymphoma. PET-CT axial of chest of the same patient from - Figs. 16 and $\mathbf{1 7}$, shows increased signal uptake in the right hilar node. Histology confirmed DLBCL.
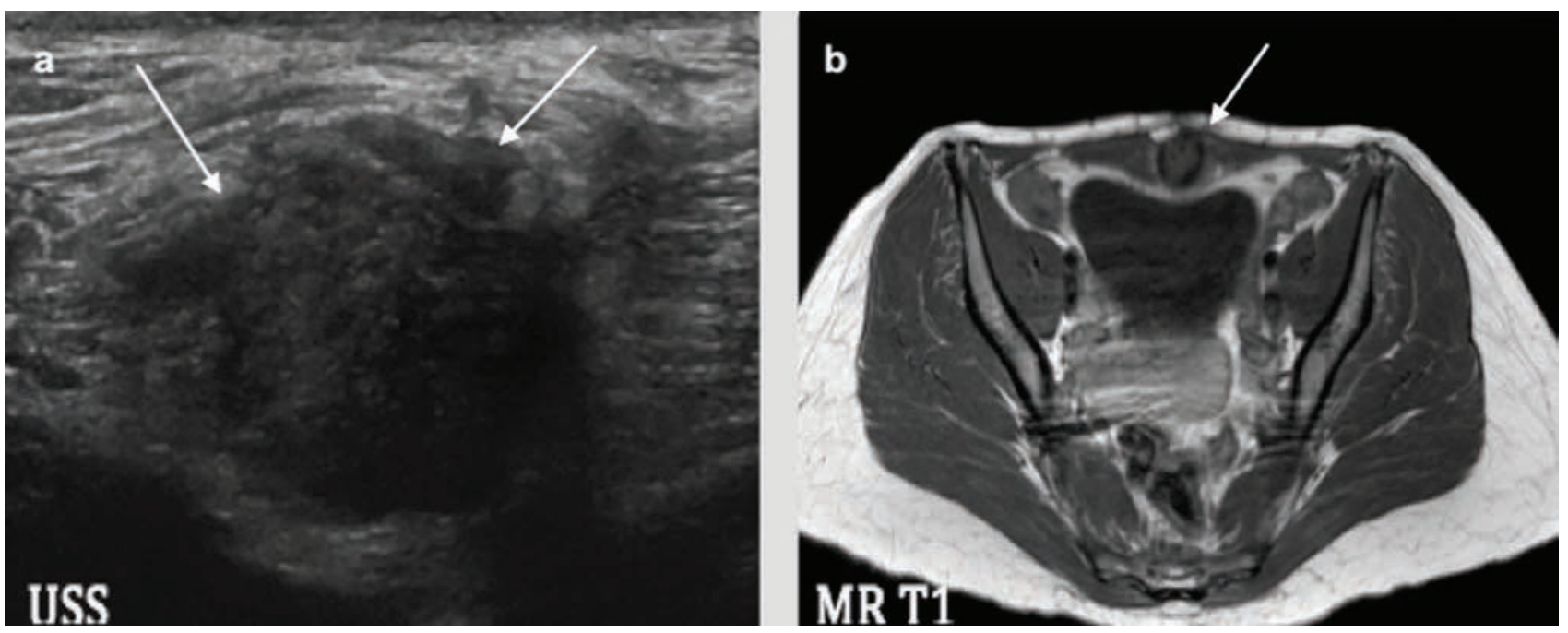

Fig. 19 Endometrioma. Ultrasound scan (USS) (a) reveals a hypoechoic mass in the ventral abdominal wall within the left rectus abdominis muscle. The lesion is isointense on T1WI (b) with signal loss peripherally (hemosiderin) in keeping with chronic hemorrhage. Histology confirmed endometrioma.
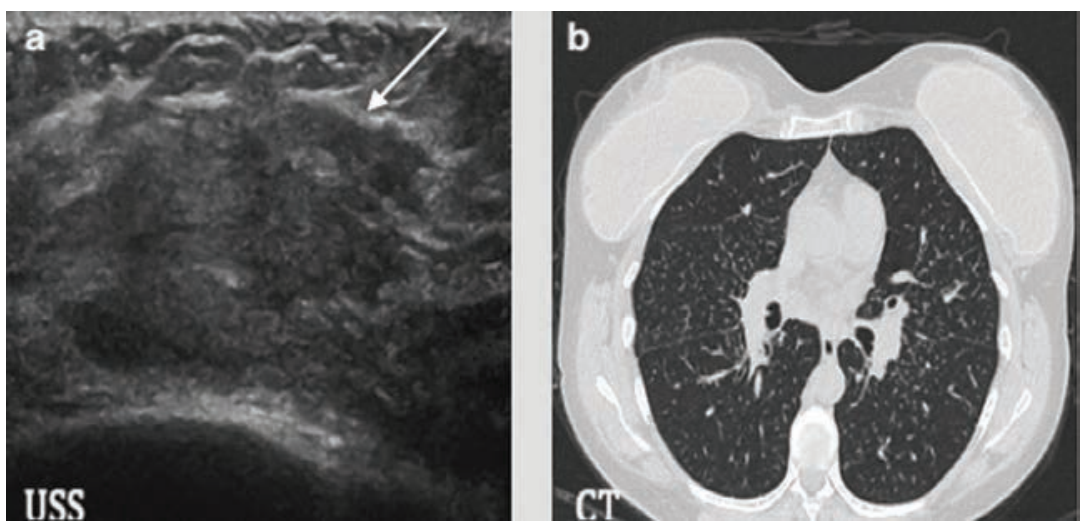

Fig. 20 Sarcoid deposit. Ultrasound scan (USS) (a) demonstrates a heterogeneous, nodular mass in the anterior abdominal wall. Subsequent CT of chest shows widespread perilymphatic nodules with interlobular septal thickening. Widespread mediastinal and hilar lymphadenopathy is also noted. (b) Findings are in keeping with sarcoidosis, which was confirmed on histology. 

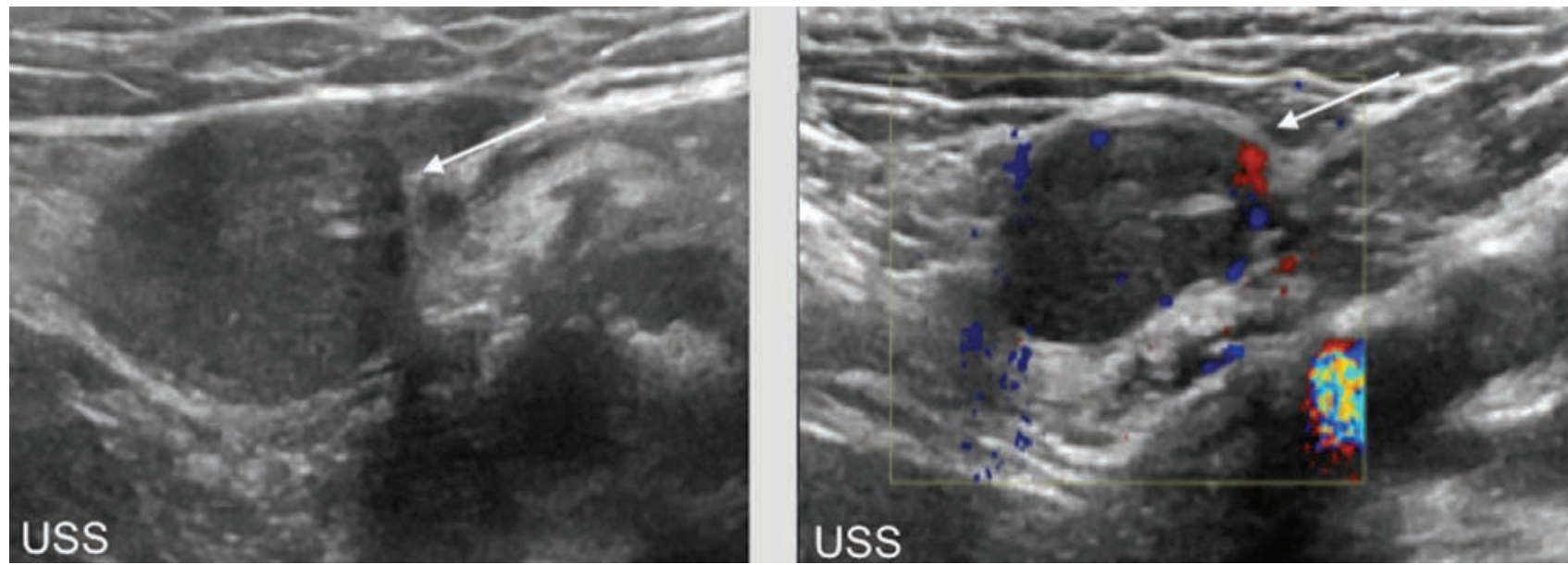

Fig. 21 Undescended testis. Ultrasound scan (USS) of left groin shows atrophic undescended testis within the inguinal canal with peripheral enhancement on Doppler.

imaging modalities can be very useful in determining the underlying cause by location and are anatomically demonstrated extremely well on either USS, CT, or MRI.

For each pathology, we have demonstrated a case example with typical features and imaging findings to guide the differential diagnosis in the evaluation of non-hernia lumps and bumps of the abdominal wall and lumbar region.

\section{Conflict of Interest}

None.

\section{References}

1 Fitzgibbons RJ Jr, Forse RA. Clinical practice. Groin hernias in adults. N Engl J Med 2015;372(8):756-763

2 Primatesta P, Goldacre MJ. Inguinal hernia repair: incidence of elective and emergency surgery, readmission and mortality. Int J Epidemiol 1996;25(4):835-839

3 Weiss SW. Lipomatous tumors. In: Weiss SW, Brooks JSJ, eds. Soft Tissue Tumors. Baltimore, MD: Williams \& Wilkins; 1996:207-251

4 Rydholm A, Berg NO. Size, site and clinical incidence of lipoma. Factors in the differential diagnosis of lipoma and sarcoma. Acta Orthop Scand 1983;54(6):929-934

5 Myhre-Jensen O. A consecutive 7-year series of 1331 benign soft tissue tumours. Clinicopathologic data. Comparison with sarcomas. Acta Orthop Scand 1981;52(3):287-293

6 Evans HL, Soule EH, Winkelmann RK. Atypical lipoma, atypical intramuscular lipoma, and well differentiated retroperitoneal liposarcoma: a reappraisal of 30 cases formerly classified as well differentiated liposarcoma. Cancer 1979;43(2):574-584

7 Fletcher CD, Unni KK, Mertens F, eds. World Health Organization Classification of Tumours. Pathology and Genetics of Tumours of Soft Tissue and Bone. Lyon, France: IARC Press; 2002

8 Kransdorf MJ, Bancroft LW, Peterson JJ, Murphey MD, Foster WC, Temple HT. Imaging of fatty tumors: distinction of lipoma and well-differentiated liposarcoma. Radiology 2002;224(1):99-104

9 Galant J, Martí-Bonmatí L, Sáez F, Soler R, Alcalá-Santaella R, Navarro M. The value of fat-suppressed T2 or STIR sequences in distinguishing lipoma from well-differentiated liposarcoma. Eur Radiol 2003;13(2):337-343

10 Hosono M, Kobayashi H, Fujimoto R, et al. Septum-like structures in lipoma and liposarcoma: MR imaging and pathologic correlation. Skeletal Radiol 1997;26(3):150-154
11 Bullough P. Orthopedic Pathology. 4th ed. New York, NY: Mosby; 2004:445-446

12 Vincent LM, Parker LA, Mittelstaedt CA. Sonographic appearance of an epidermal inclusion cyst. J Ultrasound Med 1985;4(11):609-611

13 Hong SH, Chung HW, Choi JY, Koh YH, Choi JA, Kang HS. MRI findings of subcutaneous epidermal cysts: emphasis on the presence of rupture. AJR Am J Roentgenol 2006;186(4):961-966

14 Brenner JS, Cumming WA, Ros PR. Testicular epidermoid cyst: sonographic and MR findings. (letter) AJR Am J Roentgenol 1989;152(6):1344

15 Dutta S, Sanjay P, Jones ML. Diagnosis and treatment of giant lateral abdominal wall haematoma after blunt trauma: a case report. Cases J 2009;2:9358

16 Sullivan LEJ, Wortham DC, Litton KM. Rectus sheath hematoma with low molecular weight heparin administration: a case series. BMC Res Notes 2014;7:586

17 Cherry WB, Mueller PS. Rectus sheath hematoma: review of 126 cases at a single institution. Medicine (Baltimore) 2006;85(2):105-110

18 Kayrak M, Bacaksiz A, Yazici M. Is enoxaparin injection from the abdominal wall safe in elderly people? A fatal case of rectus sheath hematoma. Can Fam Physician 2008;54(9):1246-1248

19 Reid GD, Cooper MJ, Parker J. Implications for port placement of deep circumflex iliac artery damage at laparoscopy. J Am Assoc Gynecol Laparosc 1999;6(2):221-223

20 Klingler PJ, Wetscher G, Glaser K, Tschmelitsch J, Schmid T, Hinder RA. The use of ultrasound to differentiate rectus sheath hematoma from other acute abdominal disorders. Surg Endosc 1999;13(11):1129-1134

21 Hrehorovich PA, Franke HR, Maximin S, Caracta P. Malignant peripheral nerve sheath tumor. Radiographics 2003;23(3):790-794

22 Wick MR, Swanson PE, Scheithauer BW, Manivel JC. Malignant peripheral nerve sheath tumor. An immunohistochemical study of 62 cases. Am J Clin Pathol 1987;87(4):425-433

23 Daimaru Y, Hashimoto H, Enjoji M. Malignant peripheral nerve-sheath tumors (malignant schwannomas). An immunohistochemical study of 29 cases. Am J Surg Pathol 1985;9(6):434-444

24 Murphey MD, Smith WS, Smith SE, Kransdorf MJ, Temple HT. From the archives of the AFIP. Imaging of musculoskeletal neurogenic tumors: radiologic-pathologic correlation. Radiographics 1999;19(5):1253-1280

25 Sondak VK, Economou JS, Eilber FR. Soft tissue sarcomas of the extremity and retroperitoneu advances in management. Adv Surg 1991;24:333-359 
26 Malawer MM, Sugarbaker PH. Musculoskeletal Cancer Surgery. The Netherlands: Springer; 2001:165-178

27 Vandevenne JE, De Schepper AM, De Beuckeleer L, et al. New concepts in understanding evolution of desmoid tumors: MR imaging of 30 lesions. Eur Radiol 1997;7(7):1013-1019

28 Mantello MT, Haller JO, Marquis JR. Sonography of abdominal desmoid tumors in adolescents. J Ultrasound Med 1989;8(8):467-470

29 Brooks AP, Reznek RH, Nugent K, Farmer KC, Thomson JP, Phillips RK. CT appearances of desmoid tumours in familial adenomatous polyposis: further observations. Clin Radiol 1994;49(9):601-607

30 GoldJS, AntonescuCR, Hajdu C, et al.Clinicopathologic correlates of solitary fibrous tumors. Cancer 2002;94(4):1057-1068

31 Vallat-Decouvelaere AV, Dry SM, Fletcher CD. Atypical and malignant solitary fibrous tumors in extrathoracic locations: evidence of their comparability to intra-thoracic tumors. Am J Surg Pathol 1998;22(12):1501-1511

32 Hasegawa T, Matsuno Y, Shimoda T, Hasegawa F, Sano T, Hirohashi S. Extrathoracic solitary fibrous tumors: their histological variability and potentially aggressive behavior. Hum Pathol 1999;30(12):1464-1473

33 Cardinale L, Allasia M, Ardissone F, et al. CT features of solitary fibrous tumour of the pleura: experience in 26 patients. Radiol Med (Torino) 2006;111(5):640-650

34 Wignall OJ, Moskovic EC, Thway K, Thomas JM. Solitary fibrous tumors of the soft tissues: review of the imaging and clinical features with histopathologic correlation. AJR Am J Roentgenol 2010;195(1):W55-62

35 Ginat DT, Bokhari A, BhattS, Dogra V.Imaging features of solitary fibrous tumors. AJR Am J Roentgenol 2011;196(3):487-495

36 Gidwaney R, Badler RL, Yam BL, et al. Endometriosis of abdominal and pelvic wall scars: multimodality imaging findings, pathologic correlation, and radiologic mimics. Radiographics 2012;32(7):2031-2043

37 James WD, Berger TG, Elston DM. Andrews' Diseases of the Skin: Clinical Dermatology. Philadelphia, PA: Saunders; 2006:628-630

38 Beaman FD, Kransdorf MJ, Andrews TR, Murphey MD, Arcara LK, Keeling JH. Superficial soft-tissue masses: analysis, diagnosis, and differential considerations. Radiographics 2007;27(2):509-523

39 Tuoheti Y, Okada K, Osanai T, et al. Skeletal muscle metastases of carcinoma: a clinicopathological study of 12 cases. Jpn J Clin Oncol 2004;34(4):210-214

40 Yoshimura $\mathrm{Y}$, Isobe $\mathrm{K}$, Koike $\mathrm{T}$, Arai $\mathrm{H}$, Aoki $\mathrm{K}$, Kato $\mathrm{H}$. Metastatic carcinoma to subcutaneous tissue and skeletal muscle: clinicopathological features in 11 cases. Jpn J Clin Oncol 2011;41(3):358-364

41 Patlas M, Hadas-Halpern I, Libson E. Imaging findings of extraosseous multiple myeloma. Cancer Imaging 2002; 2(2):120-122
42 Kwee TC, Kwee RM, Nievelstein RA. Imaging in staging of malignant lymphoma: a systematic review. Blood 2008;111(2):504-516

43 Lee WK, Lau EW, Duddalwar VA, Stanley AJ, Ho Y. Abdominal manifestations of extranodal lymphoma: spectrum of imaging findings. AJR Am J Roentgenol 2008;191(1):198-206

44 Yu RS, Zhang WM, Liu YQ. CT diagnosis of 52 patients with lymphoma in abdominal lymph nodes. World J Gastroenterol 2006;12(48):7869-7873

45 Metser U, Goor O, Lerman H, Naparstek E, Even-Sapir E. PET-CT of extranodal lymphoma. AJR Am J Roentgenol 2004;182(6):1579-1586

46 de Jong PA, van Ufford HM, Baarslag HJ, et al. CT and 18F-FDG PET for noninvasive detection of splenic involvement in patients with malignant lymphoma. AJR Am J Roentgenol 2009;192(3):745-753

47 Patterson GK, Winburn GB. Abdominal wall endometriomas: report of eight cases. Am Surg 1999;65(1):36-39

48 Pados G, Tympanidis J, Zafrakas M, Athanatos D, Bontis JN. Ultrasound and MR-imaging in preoperative evaluation of two rare cases of scar endometriosis. Cases J 2008;1(1):97

49 Wolf Y, Haddad R, Werbin N, Skornick Y, Kaplan O. Endometriosis in abdominal scars: a diagnostic pitfall. Am Surg 1996;62(12):1042-1044

50 Hensen JH, Van Breda Vriesman AC, Puylaert JB. Abdominal wall endometriosis: clinical presentation and imaging features with emphasis on sonography. AJR Am J Roentgenol 2006;186(3):616-620

51 Coley BD, Casola G. Incisional endometrioma involving the rectus abdominis muscle and subcutaneous tissues: CT appearance. AJR Am J Roentgenol 1993;160(3):549-550

52 Warshauer DM, Lee JK. Imaging manifestations of abdominal sarcoidosis. AJR Am J Roentgenol 2004;182(1):15-28

53 Otake S. Sarcoidosis involving skeletal muscle: imaging findings and relative value of imaging procedures. AJR Am J Roentgenol 1994;162(2):369-375

54 Lewis PJ, Salama A. Uptake of fluorine-18-fluorodeoxyglucose in sarcoidosis. J Nucl Med 1994;35(10):1647-1649

55 Tasian GE, Copp HL, Baskin LS. Diagnostic imaging in cryptorchidism: utility, indications, and effectiveness. J Pediatr Surg 2011;46(12):2406-2413

56 Frush DP, Sheldon CA. Diagnostic imaging for pediatric scrotal disorders. Radiographics 1998;18(4):969-985

57 Yeung CK, Tam YH, Chan YL, Lee KH, Metreweli C. A new management algorithm for impalpable undescended testis with gadolinium enhanced magnetic resonance angiography. J Urol 1999;162(3 Pt 2):998-1002

58 Kantarci M, Doganay S, Yalcin A, Aksoy Y, Yilmaz-Cankaya B, Salman B. Diagnostic performance of diffusion-weighted MRI in the detection of nonpalpable undescended testes: comparison with conventional MRI and surgical findings. AJR Am J Roentgenol 2010;195(4):W268-73 